\title{
If They Like It They Can Take It With Them: A Mixed Methods Examination of Internet-Based Mindfulness Meditation With Incarcerated Youth
}

\author{
Michelle Evans-Chase
}

\begin{abstract}
The most successful programming offered in juvenile justice facilities does not easily transfer back to communities to give youth the opportunity to practice intervention skills once they return home. This transferability is particularly important to youth leaving state custody given that they disproportionately return to poor communities and disrupted families that both exacerbate behaviors associated with juvenile justice involvement and act as barriers to much needed services and support. With this in mind, a randomized controlled trial was conducted with a sample of 60 youth, ages 16 to 22, sentenced to state custody in a juvenile detention facility in New Jersey to quantitatively assess the ability of freely available Internet-based mindfulness meditation instruction to increase mindfulness. Weekly journals and open-ended post-test questions were used to qualitatively explore treatment experiences. Differences among age and treatment groups on quantitative measures of mindfulness, along with content analysis of journal entries, suggest that the Internet delivery of mindfulness meditation instruction increased mindfulness in older youth. Forty percent of treatment youth, compared to $5 \%$ of control youth, provided at least one detailed entry describing their use of "class skills" to help them deal with conflict in the facility. These findings suggest that an Internet delivery of mindfulness meditation is engaging to incarcerated youth, helpful to them in coping with life in a juvenile justice facility, and able to increase mindfulness in older youth who practice it.
\end{abstract}

Keywords: Internet, mindfulness meditation, juvenile justice, transition, incarceration, youth

Approximately 60,000 youth were detained in juvenile justice facilities in 2012 (Hockenberry, Sickmund, \& Sladky, 2015). Previous cohorts of youth leaving state custody have reported difficulties with anger management $(80 \%)$, anxiety $(61 \%)$, depression (59\%), substance abuse (68\%), and suicidal ideation $(27 \%)$ at the time of their release (Sedlak \& McPherson, 2010; Snyder \& Sickmund, 2006). These findings are important given that incarcerated youth are disproportionately exposed to family and community environments out of custody known to exacerbate these and other poor mental health and behavioral outcomes. Additionally, such experiences, which include exposure to family and community violence (Baglivio et al., 2014; Hawkins et al., 2000), family disruption (Baglivio et al., 2014; Travis, Cincotta, \& Solomon, 2003), and poverty (Snyder \& Sickmund, 2006), often act as barriers to obtaining the services and support youth need to deal with these issues once they return home. Until those structural factors that give rise to these circumstances (e.g., poverty, institutional racism) are addressed, identifying ways to provide youth with support both in and outside of custody is one operative way to address the impact that these experiences have on youth.

Michelle Evans-Chase, Ph.D., is an Assistant Professor of Psychology at Rowan University in Glassboro, NJ. 116 Robinson Hall, Rowan University 201 Mullica Hill Road • Glassboro, New Jersey 08028. Email: evanschase@rowan.edu 
The purpose of this study is to identify an effective intervention for incarcerated youth that 1) increases their ability to cope with the stressors that exacerbate the emotional and behavioral problems associated with juvenile justice involvement and 2) is delivered in such a way that they have continued, free access after release, regardless of family or community resources. The intervention chosen for the study, mindfulness meditation, is a practice associated with positive mental, behavioral, and emotional changes in samples of adults and youth with and without mental health diagnoses, and it is amenable to an Internet delivery method that would allow for continued practice once youth leave custody.

\section{Background and Significance}

It is well documented that incarcerated youth face disproportionately high rates of community and family stressors outside of custody known to increase the likelihood of delinquent and aggressive behavior (Baglivio et al., 2014; Bjerk, 2007; Carlson, 2006; Smith \& Ecob, 2007). These experiences, which are enduring factors in the lives of incarcerated youth, include parental incarceration (Schnittker \& John, 2007; Travis et al., 2003), violent victimization, exposure to violence (Baglivio et al., 2014; Bjerk, 2007; Carlson, 2006), and poverty (Bjerk, 2007; Carlson, 2006).

\section{Programming and Out of Custody Context}

Programming in juvenile justice facilities is an opportunity to intervene in the lives of youth and help them develop into healthy young adults. Currently, most of the successful interventions used with incarcerated youth, such as cognitive behavioral therapies and interpersonal skill development (Lipsey, Wilson, \& Cothern, 2000), are not designed to provide continued structure in the practice of newly acquired skills once youth are out of custody. Additionally, a systematic review of 198 juvenile justice intervention studies found that only five studies assessed transition or post-release programming, suggesting that transition programming is either a rare practice with youth leaving custody or that such programming is implemented with no evidence (Evans-Chase \& Zhou, 2014). What appears to be the current practice in juvenile justice facilities is to provide treatment and programming for youth only until they are released, after which ill-equipped families and communities are left responsible for finding, connecting, or providing youth with the support they need. High rates of recidivism (Snyder \& Sickmund, 2006) and longitudinal data suggest that this is not a successful strategy. One study of youth leaving custody found that, while $45 \%$ had at least one DSM-IV diagnosis, only $20 \%$ were receiving mental health services at 6 months post release and only $15 \%$ at 12 months (Bullis, Yovanoff, \& Havel, 2004). Additionally, only $48 \%$ of the cohort was connected to any community-based agencies at 6 months post release, with $33 \%$ at 12 months. Identifying mechanisms that provide access to continued support once youth leave custody could help to ensure their success while at the same time serving the goals of the juvenile justice system.

\section{Internet-based Interventions}

Previous research on technology use by adolescents has indicated that $93 \%$ of youth, regardless of income, are daily users of technology, including personal computers, iPods, cell phones, and the Internet (Palermo, Wilson, Peters, Lewandowski, \& Somhegyi, 2009). 
Despite empirical support for the use of technology in the delivery of interventions supporting adolescent physical health (Maher, Williams, Olds, \& Lane, 2010), mental health (Palermo et al., 2009), and risk reduction (Heinicke, Paxton, McLean, \& Wertheim, 2007), it is rarely used in juvenile justice interventions (Evans-Chase \& Zhou, 2014). Using computers or iPods to deliver in-custody programming could give youth leaving custody the opportunity to continue to practice intervention skills after release with the same structure, breaching the transition gap and increasing their ability to incorporate intervention skills into their everyday lives.

\section{Mindfulness Meditation}

Mindfulness meditation (MM) is a skill that has been successfully taught both with a teacher present as well as via guided meditation tapes (Ditto, Eclache, \& Goldman, 2006). Successful integration of MM into individual practice has been found with programs ranging from 45-minute sessions once per week for 4 weeks (Jain et al., 2007) to 2-hour sessions once per week for 8 weeks (Ramel, Goldin, Carmona, \& McQuaid, 2004). The three components common to most definitions of MM practice include present awareness, or having one's awareness in the present moment; nonjudgmental awareness, or being aware of but not judging the emotions, thoughts, or events of the present moment as good or bad; and acceptance, or accepting the emotions, thoughts, or events of the present moment as they are (Biegel, Brown, Shapiro, \& Schubert, 2009; Burke, 2010).

Positive mental health outcomes and behavior change. Previous research on MM has found significant effects on positive states of mind and stress reduction in comparison to relaxation and control groups (Broderick, 2005; Jain et al., 2007). Studies have also found a positive relationship between MM and reduced substance abuse in incarcerated adults (Bowen et al., 2006) and increased self-control and self-awareness and decreased stress and anger in adolescent sex offenders (Derezotes, 2000). MM has been successfully combined with cognitive and dialectical behavior therapies as a treatment for children with anxiety (Semple, Reid, \& Miller, 2005) and for the prevention of suicidal behaviors in patients with past suicidal ideation (Williams, Duggan, Crane, \& Fennell, 2006). A recent review of research conducted between 2003-2008 found the associated effect of MM to include lowered anxiety, depression, anger and worry; a greater sense of well-being; increased emotional control; lowered levels of cortisol; and an increased ability to reduce harmful behaviors such as binge eating, smoking, and substance use (Greeson, 2009).

MM with incarcerated youth. These findings suggest that MM may be uniquely suited for use in the juvenile justice system given its successful use with adolescents and as an effective treatment for youth with behavioral and emotional problems similar to those reported by youth leaving custody. Furthermore, given the effectiveness of MM in addressing mental health issues such as suicidal ideation, depression, and anxiety in a variety of populations, MM should be no less effective and may even be more helpful for those youth incarcerated in the juvenile justice system with undiagnosed and/or untreated mental health issues. Finally, the increased emotional and behavioral control associated with MM may be protective against the emotional responses associated with the life stressors incarcerated youth face outside of custody (Greeson, 2009). 


\section{Methods}

As part of a randomized, controlled trial of the effects of MM on self-regulation, the current study explores participants' experiences with the Internet-based instruction qualitatively through content analysis of journals and open-ended questions and quantitatively using the Five-Factor Mindfulness Questionnaire (FFMQ). For a full description of study methods, see Evans-Chase (2013).

\section{Recruitment and Randomization}

All male juvenile offenders incarcerated in the New Jersey state correctional facility in Monroe Township, NJ who were scheduled for release no less than 3 months from entrance into the study, who voluntarily agreed to be in the study, who voluntarily signed an assent or consent form, and who had at least one parent sign a consent form (for youth under 18) were eligible to participate in the study. Residents who were in protective custody or were otherwise not safe in a group setting, either because they were a threat to others or a high victim risk as defined by the facility, were excluded from the participant pool prior to recruitment activities.

Consent interviews were conducted with youth 18 and over, and assent interviews were conducted with youth 17 and under. Parental consent forms were sent to the parents/guardians of all youth under the age of 18 who assented to participate. The packets contained a letter of introduction, two copies of the consent form, one for the parent/guardian to keep and one for them to mail to the principal investigator (PI), and a stamped envelope addressed to the PI.

Randomization was done at the individual level within housing unit groups such that youth from housing units 1,2, and 3 were randomly assigned to either treatment or control groups meeting on Thursday nights and youth from housing units 4, 5, and 6 were randomly assigned to either treatment or control groups meeting on Friday nights. Housing units were combined by the facility administrators based on those units that normally mixed in other facility activities. All study activities were held in the same community building, including recruitment, randomization, treatment and control sessions, and data collection. The randomization process itself used a list of numbers, with even numbers representing Mindfulness Meditation assignment and odd numbers representing Guided Relaxation (GR) assignment. Each number was written on an individual piece of paper, folded, and placed in a small paper bag. At the end of the pretest session, as each participant turned in his completed questionnaire he was asked to pick one of the pieces of paper out of the bag. The number chosen indicated group assignment. Randomization was conducted in this fashion for three reasons: 1) to give the participants a clearer understanding of what was meant by random assignment to groups, 2) to give the participants an opportunity to feel that they were a part of the study process, and 3) because conducting the randomization process after administration of the pretest has been identified as a method that can prevent the impact that knowledge of group assignment can have (Boruch, 1997). 


\section{Treatment and Control Sessions}

Classes were conducted for 1 hour once per week for 8 weeks. A male Research Assistant used pre-recorded instructions to facilitate treatment and control group sessions. Participants sat in chairs at the table of their choosing. All of the chairs faced the front of the room where the iPod and speaker were placed on a centrally located table. Snacks provided by the facility were also made available during the sessions. The Research Assistant handed out the journals, took roll, and turned on the audio for that session. The journals were handed out at the beginning of the session to give participants something to do (doodle, draw, write) if they found it difficult to sit still during the entire audio session. This procedure was planned in recognition of the high rates of Attention Deficit Disorder in this population (Adams, 2010) to allow them to continue to listen while also engaging in a physical activity that would not be disruptive to the other participants. MM classes used MP3 downloads of classes led by Noah Levine, who has extensive experience teaching meditation to incarcerated youth and adults as well as non-incarcerated youth recovering from drug and alcohol addiction. The downloads used for the study, all of which are available for free on Levine's website (Levine, 2015), involved specific instructions in MM that encouraged relaxed, nonjudgmental awareness of thoughts and feelings while focusing on breathing. The instruction also included commentary on how these MM practices (nonjudgmental awareness of thoughts and feelings during meditation) relate to compassion, patience, and mindfulness in everyday life.

GR classes utilized a Progressive Muscle Relaxation (PMR) MP3 download that included very simple instructions in contracting and relaxing different muscle groups in a conscious attempt to relax the body and reduce cognitive and physiological stress (Pawlow \& Jones, 2005). Progressive Relaxation has been found to significantly lower levels of salivary cortisol after a single 1-hour session (Pawlow \& Jones, 2005) and, in metaanalysis, to have a medium-high effect on anxiety, particularly for young people (Manzoni, Pagnini, Castelnuovo, \& Molinari, 2008). While PMR and meditation both significantly reduce anxiety (Manzoni et al., 2008), the practice of MM is additionally associated with "important shifts in cognition, emotion, biology, and behavior" (Greeson, 2009, p. 15). It is this change in behavior, cognition, emotion, and biology that was hypothesized for the treatment group but not for the control group. That both the treatment and control groups might experience decreases in anxiety was an additional benefit of the choice of PMR (termed Guided Relaxation for the study) for the control group such that it provided the possibility that the comparison group might benefit from participation in the study, although no stress or anxiety scales were included in data collection materials.

\section{Incentives}

To thank participants for their participation, snacks were provided during data collection and class sessions. Additionally, gift cards were provided based on level of participation: $\$ 5$ for the pre-test, $\$ 5$ for attending 5 or more classes or $\$ 10$ for attending all 8 classes, and $\$ 5$ for the post-test. Participants were asked at post-test to identify a store or restaurant for which they would like a gift card purchased in the amount corresponding to their level of participation in the study. 


\section{Measures}

To test the novel delivery of MM instruction, a quantitative measure assessing changes in mindfulness between pre and post-test and qualitative measures exploring the experience of the delivery method were used.

The 5-Facet Mindfulness Questionnaire (FFMQ). The FFMQ includes 5 subscales that measure different facets of mindfulness, including Observing, Describing, Acting with Awareness, Nonjudging of Inner Experience, and Nonreactivity to Inner Experience. The FFMQ was designed for use with a range of ages and has been used successfully with both children (E. Sabinga, personal communication, March 5, 2010) and young adults (Baer et al., 2008).

Construct validity of the five facets has been demonstrated in a sample of older adolescent and adult students, where the Describing, Acting with Awareness, Nonjudging of Inner Experience, and Nonreactivity facets were significantly and negatively correlated with psychological symptoms and significantly and positively correlated with psychological well-being (Baer et al., 2008). The Observe facet was positively and significantly correlated with psychological symptoms in those with more meditation experience but not amongst those with little or no meditation experience. It appears that the Observing facet has different meanings in experienced versus inexperienced meditators such that Observing for non-meditators represents a more negative self-focus that can be maladaptive, while in experienced meditators, Observing involves an internal and external focus that is non-judgmental (Baer et al., 2008).

Journals. Journals were handed out at the beginning and collected at the end of each class session and included a closed-ended section in which participants were asked to circle the number of times they had practiced between classes and an open-ended section in which they were asked to write down any thoughts, experiences, or suggestions about the class. Any practice done between classes would, by necessity, be from memory, as participants had no access to computers or the Internet, nor were they given the name of the MM or GR instructor until the classes were completed. To assure that identical instructions were given to treatment and control groups, the following was read during the initial class sessions:

We will meet each week to do this but in between classes you can practice (MM or GR) as much or as little as you want to. The only thing we ask is that you keep track of how many times you practice. Each week before I start the MP3 instructions I will hand out these journals for you to keep track of whether you practiced between classes or not and if you did, how many times. You can also use the journals to write down anything about the classes that you think would be important for the researcher to know.

\section{Treatment Experience}

Six open-ended questions were presented at post-test to the MM participants; these questions asked for general opinions about their experiences with the intervention. The questions asked what they liked most and least about the classes, if and how learning MM helped them deal with everyday life, if they would be interested in participating in more 
classes, and if/how they thought being at a juvenile facility affected the ability to practice MM.

\section{Data Analysis}

Multiple Regression analysis was used to test the effect of the MM instruction on mindfulness using four dummy variables: three for age: age1 (age 16-17), age2 (age 18), and age 3 (age 19-23) and one for group assignment. Two models tested differences between groups in mindfulness post-test scores: a Main Effects model that included pretest scores, a treatment dummy variable, and two of three age group dummy variables; and an Interaction Model that added an interaction term (agextreat) created by multiplying the age group dummy variables by the treatment dummy variable.

The author used an iterative, open coding process to identify topics and themes arising from the MM journals and post-test open-ended questions. The content analysis process included multiple readings of the narrative data (i.e., journal entries and post-test answers), with the first reading done without expectation of what topics or themes might arise. During the second reading, topics were noted for each entry or answer and then transferred to a database in Microsoft Excel. Topics were then explored for key concepts or words, and themes were created out of related topics. Entries were then re-read for the existence of the main themes or key concepts across participants. Content analysis was done first for the MM group and followed by analysis of GR narrative data for the frequency with which youth in the GR group addressed the most common themes identified in the MM data as well as for common topics and themes within GR journal entries.

\section{Human Subjects}

The risk to the participants was minimal. Participation in Mindfulness Meditation or Guided Relaxation does not include any risk greater than that faced in everyday life in the facility. However, because of the vulnerability of incarcerated youth, several procedures were implemented to ensure that participation was truly voluntary. First, although the state is the legal guardian of the youth and able to give consent for their participation, assent forms were used to make sure that each youth was completely informed about the study and participated voluntarily. Parents of all assenting youth were contacted and asked to

provide consent for their son's participation in the study. Second, to assure that any youth who declined to participate did not face any consequences for declining, both the PI and Research Assistant referred to youth who declined as "not qualifying" when communicating with the facility rather than saying that the youth declined to participate. This terminology is consistent with and reflective of the study Entrance Criteria, which includes voluntary participation and a voluntarily signed assent form. All procedures were approved by the University of Pennsylvania Institutional Review Board and the New Jersey Juvenile Justice Commission Research Review Board. 


\section{Results}

A total of 60 young men participated in the study. The mean age of the overall sample was age $18(s d=1.30)$, with $17(28 \%)$ in the age $16-17$ group, $24(40 \%)$ in the age 18 group, and $19(32 \%)$ in the age 19-23 group. Of the 60 participants who started the study, $45 \%$ $(n=27)$ completed the study through the post-test and are used in quantitative analysis. Attrition from the study and thus exclusion from the quantitative analysis was most commonly due to being out of custody at the time of the post-test $(n=17,29 \%)$, not attending the post-test session $(\mathrm{n}=9,15 \%)$, or being on lockdown on the day of the posttest $(n=3,5 \%)$. All journals with at least one entry were included in the analysis.

\section{Treatment vs. Control: Mindfulness}

A paired samples t-test was used to establish equivalence between the mean scores for the two groups (MM vs. GR) on baseline mindfulness. No significant differences were found between the MM $(M=122.71, S D=19.80)$ and $\mathrm{GR}(M=124.58, S D=11.16)$ groups, $t$ $(24)=0.289, p=0.77$. Multiple Regression analysis was used to test models of differences between groups at post-test using four dummy variables: 3 for age: age 1 (age 16-17=1, age $18-23=0$ ), age 2 (age $18=1$, age $16-17=0$, age 19-23=0), and age 3 (age 19-23=1, age 16$18=0)$; and one for group assignment: treatgrp $(1=$ treatment, $0=$ control $)$. The age groupings were made 1) based on common separations in brain imaging studies of developmental differences in those areas most affected by MM practice (Allen et al., 2012; Holzel et al., 2007; Luna, Padmanabhan, \& O'Hearn, 2010; Tang, Lu, Fan, Yang, \& Posner, 2012), 2) to allow for contrast with multiple referent groups (Gordon, 2010), and 3) to create more equal groupings for analysis (Gordon, 2010).

Because the developer of the FFMQ has recommended that the Observing sub-scale be used only in comparisons within treatment groups when evaluating mindfulness programs due to possible differences in meaning for those with more MM experience (Baer, Samuel, \& Lykins, 2011), two datasets were used to test four models. Two models used the original mindfulness scores, including the Observing sub-scale, and three models used a dataset of scores with the Observe sub-scale removed from both pre and post-test totals. The Main Effect Only model for each dataset tested the effect of being in the treatment versus the control group, controlling for pre-test scores and age group; the Interaction Model included these variables plus an interaction term for age group $\mathrm{x}$ treatment group.

As demonstrated in Table 1 using all of the sub-scales, the GR group significantly outperformed the MM group in the oldest age group by an average of 15 points $(p<0.05)$, a difference that did not hold once the Observe sub-scale was removed $(B=-11.57, p>.05)$. The age $2 \mathrm{MM}$ youth (comprised of youth aged 18) also outperformed the age $3 \mathrm{MM}$ youth (comprised of youth age 19-23) by almost 21 points $(p<0.05)$ using the full Mindfulness scale, but the difference was both smaller and non-significant with the reduced scale $(B=$ $13.86, \mathrm{p}>0.05)$. 
Table 1. Regression analysis of Mindfulness scores using the full scale and reduced scale with the Observe sub-scale removed from post-test totals.

\begin{tabular}{|c|c|c|c|c|}
\hline & \multicolumn{2}{|c|}{$\begin{array}{l}\text { Original } \\
\text { Main Effects }\end{array}$} & \multicolumn{2}{|c|}{$\begin{array}{l}\text { Adjusted } \\
\text { Main Effects }\end{array}$} \\
\hline & $\mathrm{B}(\mathrm{SE})$ & $\mathrm{B}(\mathrm{SE})$ & $\mathrm{B}(\mathrm{SE})$ & $\mathrm{B}(\mathrm{SE})$ \\
\hline Pretest & $0.66(0.15)^{*}$ & $0.70(0.15)^{*}$ & $0.58(0.15)^{*}$ & $0.60(0.16)^{*}$ \\
\hline Treat v Control & $-4.91(4.29)$ & & $-3.81(3.73)$ & \\
\hline Treat v Control Age1 & & $-4.56(8.13)^{\mathrm{o}}$ & & $-2.25(7.93)^{2}$ \\
\hline Treat v Control Age2 & & $5.09(6.51)^{\mathrm{a}}$ & & $2.29(6.06)^{3}$ \\
\hline Treat v Control Age3 & & $-15.68(6.55)^{*}$ & & $-11.57(6.12)$ \\
\hline Age1 & $-8.41(5.7)$ & $-12.62(7.5)$ & $-4.89(4.85)$ & $-8.63(7.14)$ \\
\hline Age2 & $-3.55(4.95)$ & $-12.31(5.95)$ & $-3.52(4.41)$ & $-9.28(5.59)$ \\
\hline Age1xTreat & & $11.12(10.59)$ & & $9.31(10.09)$ \\
\hline Age $2 x$ Treat & & $20.77(9.03)^{*}$ & & $13.86(8.54)$ \\
\hline Age1xTreat $^{1}$ & & $-9.65(10.75)^{\mathrm{a}}$ & & $-4.54(10.45)^{3}$ \\
\hline Intercept & $45.05(18.95)^{*}$ & $43.81(18.78)^{*}$ & $45.39(15.64)^{*}$ & $45.42(17.02)^{*}$ \\
\hline $\mathrm{N}$ & 24 & 24 & 24 & 24 \\
\hline Adj R2 & 0.53 & 0.60 & 0.42 & 0.45 \\
\hline F-Value & $\mathrm{F}(4,19)=7.42^{*}$ & $\mathrm{~F}(6,17)=6.69^{*}$ & $\mathrm{~F}(4,19)=5.22^{*}$ & $\mathrm{~F}(6,17)=4.07^{*}$ \\
\hline$\Delta \mathrm{AdjR} 2$ & & 0.07 & & 0.03 \\
\hline F-Value & & $\mathrm{F}(2,17)=1.46$ & & $\mathrm{~F}(2,17)=0.31$ \\
\hline$* \mathrm{p}<0.05$ & & ${ }^{1}$ with age & as the reference & oup \\
\hline${ }^{\mathrm{a}}$ Intercept: $\mathrm{B}=31.50, \mathrm{SE}$ & $=18.45, \mathrm{p}>0.05$ & ${ }^{2}$ Intercept & $\mathrm{B}=36.79, \mathrm{SE}=16$ & $6, p<0.05$ \\
\hline${ }^{\circ}$ Intercept: $\mathrm{B}=31.19, \mathrm{SE}$ & $=19.53, \mathrm{p}>0.05$ & ${ }^{3}$ Intercept & $\mathrm{B}=36.14, \mathrm{SE}=16$ & $3, p<0.05$ \\
\hline
\end{tabular}

\section{Content Analysis: Journal Entries}

Table 2 lists the most common themes found in the MM journals. Comparisons with GR journals indicated that a higher percentage of youth in the MM classes wrote about the application of class skills to help them control their behavior or deal with their emotions outside of class (54\% v. 30\%), with an even bigger gap between the two groups in the percentage of youth who described specific examples in which they used class skills to regulate their emotions or behavior outside of class $(42 \% \mathrm{v} .5 \%)$. A higher percentage of youth in the GR classes reported that practicing class skills both inside and outside of class reduced their stress levels and/or made them feel calm or relaxed (65\% v. $58 \%)$. 
Table 2. Primary Themes Compared Across Treatment Conditions

\begin{tabular}{lcc}
\hline & \multicolumn{2}{c}{$\begin{array}{c}\text { Number of } \\
\text { Participants* }\end{array}$} \\
\cline { 2 - 3 } & $\mathrm{MM}$ & $\mathrm{GR}$ \\
$\mathrm{n}=24$ & $\mathrm{n}=20$ \\
\hline Described using class skills to self-regulate behavior or emotions & $13(54 \%)$ & $6(30 \%)$ \\
Described specific examples of self-regulating emotions or behavior & $10(42 \%)$ & $1(5 \%)$ \\
Reduced stress, were calmed by class or practice outside of class & $14(58 \%)$ & $13(65 \%)$ \\
Neither & $4(17 \%)$ & $2(10 \%)$ \\
\hline * Some participant journals contained multiple themes, therefore column totals $>$ number of \\
participants
\end{tabular}

As demonstrated in Figure 1, about half of the MM participants $(n=12)$ had journal entries that communicated only positive experiences and thoughts about the class or the use of meditation or mindfulness skills outside of class. About $38 \%(n=9)$ had primarily positive journal entries mixed with entries that communicated factors about the class that they did not like. One primary complaint about the class was that it was boring $(n=3)$, although two of these three participants also commented in their journals that, while they found the class boring, they still practiced the MM instructions outside of class and found that it helped them relax and control their anger. A second complaint was that it was difficult to hear the instructions because of the volume of the iPod $(n=3)$ or that the speaker's voice on the iPod was sometimes hard to understand $(n=2)$. Of the 10 participants who wrote negative comments, nine also included positive experiences of class participation. All of the participants who described practicing MM outside of class, regardless of their feelings towards the class itself, reported only positive experiences in applying class skills to difficult situations encountered in their day-to-day lives in the facility.

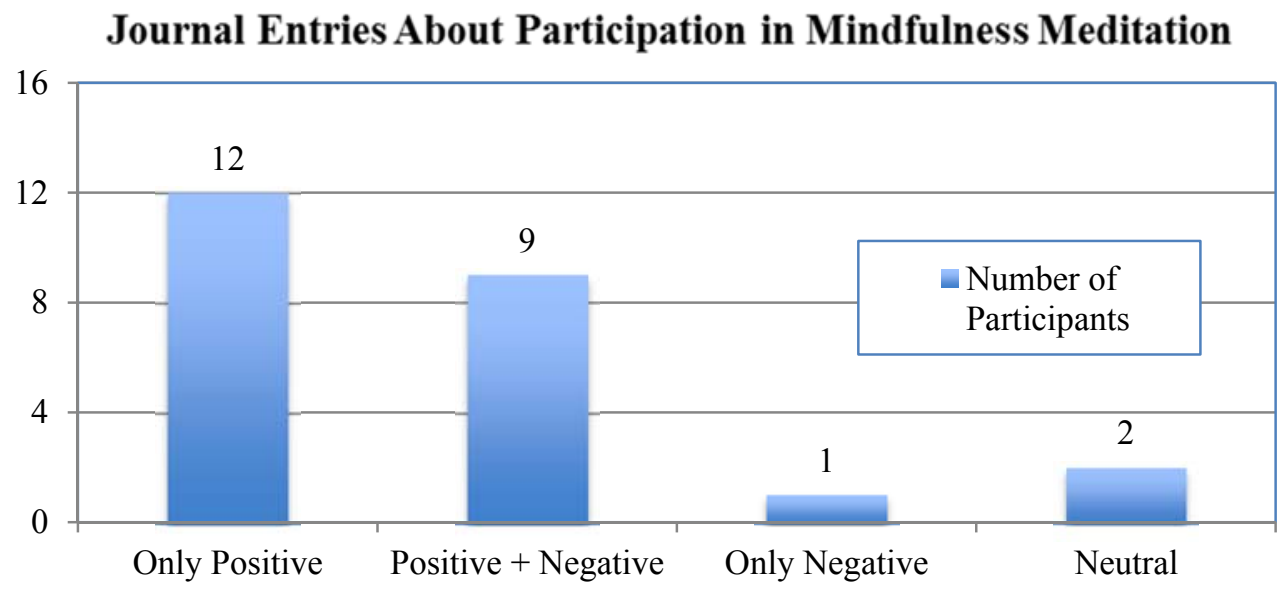

Figure 1. Journal commentary about participation in Mindfulness Meditation Classes Across All Entries 


\section{Treatment Engagement}

Youth in the MM group were asked open-ended questions at post-test about their experiences in the class. In response to the question What part of the meditation classes did you enjoy most?, $60 \%(n=9)$ indicated that it was the intervention activity itself that they liked the most, $27 \%(n=4)$ indicated that it was the class time spent interacting with other participants or eating the snacks provided by the Research Assistant that they liked most, and $13 \%(n=2)$ provided a response too ambiguous to interpret (see Figure 2).

\section{What did you like most?}

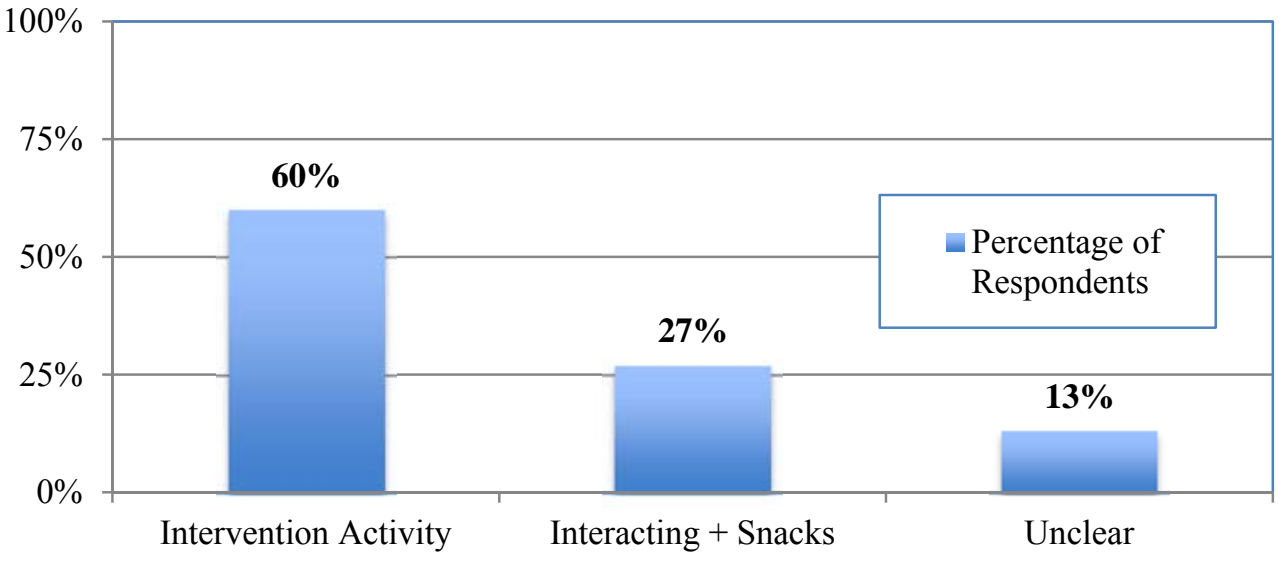

\section{Figure 2. Percentage of Respondents Reporting What They Liked Most About the Mindfulness Meditation Classes.}

In response to the question What part of the meditation classes did you not like?, $47 \%$ $(n=7)$ indicated that there was nothing about the classes that they did not like, $33 \%(n=5)$ indicated that they had some difficulty with the sound of the intervention delivery, and $7 \%$ $(n=1)$ indicated that he found the classes boring. In response to the question Did learning mindfulness meditation help you deal with everyday life?, 67\% $(n=10)$ indicated that learning MM helped them deal with the stressors that they faced living in a juvenile justice facility by helping them control or be aware of their own behavior in emotional situations, and/or by helping them stay out of trouble. In response to the question Would you be interested in participating in more classes if they were offered at the [facility]?, 93\% $(n=14)$ indicated that they would be interested. In response to the question Do you think being in a juvenile justice facility makes it hard to practice MM?, $60 \%(n=9)$ reported that practicing MM was hard because of the difficulty in finding a quiet place where they would not be bothered, and $40 \%(n=6)$ reported that it was not difficult, that it is something particularly well suited to juvenile justice facilities. 


\section{Discussion}

Findings from this study provide support for a new method of MM instruction for incarcerated youth. Using the Internet in this fashion could increase the ability of juvenile justice facilities to not only provide MM instruction in custody but also provide a longer period of transitional support for youth leaving custody such that the instruction is freely accessible on the Internet, giving youth the opportunity to continue to practice intervention skills using the same instructions and teacher after release that they became familiar and comfortable with in custody.

\section{Mindfulness}

Because previous research suggests that the Observing factor has different meanings for experienced meditators, all comparisons were made using two datasets: one with Mindfulness scores including the Observe sub-scale and one with the Observe sub-scale removed. The results suggest that the Observing questions may have been understood differently at post-test by older youth in the MM group given that the oldest GR age group significantly outperformed the oldest MM group at post-test using the full scores but that the difference did not hold once the Observing sub-scale was removed. These findings may be an indication that older youth in the MM group had the qualitative change referenced by Baer and colleagues (2011) in which their experience with MM changed their understanding at post-test of what it means to observe one's emotions and reactions, that is, from one with to one without judgment.

Once the Observe scores were removed, neither model found significant differences between the MM and GR groups in any of the age groups. This is surprising given the differences found between groups in the content analysis of journal entries and the evidence of changes in the oldest MM group associated in previous research with MM experience. It may be that FFMQ questions, at least those other than the Observe sub-scale, hold different meanings in the institutional setting. There are many unique factors in custody that may impact the ability of youth to identify, without examples specific to their unique situation, how often they accept the moment as it is or have present time awareness as asked in the FFMQ. Future research is needed to test the validity of the FFMQ in measuring mindfulness with youth living in correctional settings.

\section{Journals}

Comparisons of journal entries between the MM and GR youth provide qualitative support for the ability of Internet-based MM instruction to increase mindfulness in incarcerated youth. First, over half of the youth in the MM classes wrote at least one entry mentioning the use of class skills to self-regulate emotions and behavior outside of class while less than a third of GR youth did. More compelling is the difference between the groups in providing specific, detailed examples of situations in which class skills were used and how they used them, with over $40 \%$ of MM youth providing at least one detailed example that recounted a situation in which they became angry during an interaction with a staff member or resident but took a moment to breath and think about how they wanted to respond and as a result did not react in an angry or aggressive manner. By contrast, only 
one GR youth provided such specific examples. Instead, entries describing the use of GR in the self-regulation of emotions or behavior were more likely to be general reactions unassociated with any particular situation.

The specificity and detail of the journal entries of the MM youth compared to the GR youth suggest that the MM youth may have been more aware of their behavior and able to apply what they were learning more consciously so that when the time came to write in their journals during class time, they could bring to mind and provide considerable detail of specific situations in which they found class skills helpful. Furthermore, descriptions of interpersonal situations where they became angry contained evidence of responses characteristically associated with mindfulness: awareness of thoughts and emotions (awareness), conscious decisions not to respond with anger (acceptance of situation or emotion, non-reaction), and the ability to later describe situations with detail (being present, describe).

\section{Treatment Engagement}

Programming that is found in intervention studies to be effective with youth does not always translate into effective practice unless youth themselves find the program engaging enough to be worth the effort of participation. Based on questions asked of the MM participants at post-test, it appears that the vast majority of youth found the intervention as delivered engaging. Most reported that the MM activity itself was their favorite part of the class (compared to the opportunity to socialize and eat snacks) and that the skills they learned were immediately applicable to their lives in dealing with the stress associated with living in a juvenile justice facility, in being aware of and controlling their emotional reactions, and/or in helping them stay out of trouble.

\section{Conclusion}

The level of engagement and real-life application of intervention skills demonstrated here suggests that MM instruction using MP3 downloads with youth in custody could increase their ability to cope with the stressors of life within juvenile justice facilities and possibly translate to continued practice after release when such coping mechanisms are even more imperative if youth are to thrive within their troubled families and communities. Future research should include longitudinal studies to assess the extent to which youth continue to practice mindfulness meditation once they return home and if such continued practice is associated with positive effects on mental health and behavioral outcomes. Future research should also include samples of young women and special populations of youth not represented here (i.e., those in juvenile justice substance use and mental health treatment units) and should explore the efficacy of a shorter intervention period, with multiple classes per week across fewer weeks, to address the high rate of attrition due to changes in custody status (i.e., release or transfer to a different facility) endemic to an 8week intervention in the juvenile justice system. Finally, future studies should explore the efficacy of individual delivery via personal iPods to allow for inclusion of incarcerated youth who are not safe in group settings. 


\section{References}

Adams, E. (2010). Healing invisible wounds: Why investing in trauma-informed care for children makes sense. Justice Policy Institute. Retrieved fromhttp://www.justicepolicy.org.

Allen, M., Dietz, M., Blair, K., van Beek, M., Rees, G., Vestergaard-Poulsen, P., ...Roepstorff, A. (2012). Cognitive-affective neural plasticity following activecontrolled mindfulness intervention. The Journal of Neuroscience, 32(44), 1560115610.

Baer, R., Samuel, D., \& Lykins, E. (2011). Differential item functioning on the Five Facet Mindfulness Questionnaire is minimal in demographically matched meditators and nonmeditators. Assessment, 18, 3-10.

Baer, R., Smith, G., Lykins, E., Button, D., Krietemeyer, J., Sauer, S., \& Williams, J. (2008). Construct validity of the Five Facet Mindfulness Questionnaire in meditating and nonmeditating samples. Assessment, 15, 329-342.

Baglivio, M., Epps, N., Swartz, K., Sayedul, M., Sheer, A., \& Hardt, N. (2014). The prevalence of adverse childhood experiences (ACE) in the lives of juvenile offenders. Journal of Juvenile Justice, 3, 1-23.

Biegel, G., Brown, K., Shapiro, S., \& Schubert, C. (2009). Mindfulness-based stress reduction for the treatment of adolescent psychiatric outpatients: A randomized clinical trial. Journal of Community and Clinical Psychology, 77, 855-866.

Bjerk, D. (2007). Measuring the relationship between youth criminal participation and household economic resources. Journal of Quantitative Criminology, 23, 23-39.

Boruch, R. (1997). Randomized experiments for planning and evaluation: A practical guide. Thousand Oaks, CA: Sage.

Bowen, S., Witkiewitz, K., Dilworth, T., Chawla, N., Simpson, T., Ostafin, B., ...Marlatt, A. (2006). Mindfulness meditation and substance abuse in an incarcerated population. Psychology of Addictive Behavior, 2, 343-347.

Broderick, P. (2005). Mindfulness and coping with dysphoric mood: Contrasts with rumination and distraction. Cognitive Therapy and Research, 29, 501-510.

Bullis, M., Yovanoff, P., \& Havel, E. (2004). The importance of getting started right: Further examination of the facility-to-community transition of formerly incarcerated youth. Journal of Special Education, 38, 80-94.

Burke, C. (2010). Mindfulness-based approaches with children and adolescents: A preliminary review of current research in an emergent field. Journal of Child \& Family Studies, 19, 133-144.

Carlson, K. (2006). Poverty and youth violence exposure: Experiences in rural communities. Children \& Schools, 28, 87-96. 
Derezotes, D. (2000). Evaluation of yoga and meditation training with adolescent sex offenders. Child and Adolescent Social Work Journal, 17, 97-113.

Ditto, B., Eclache, M., \& Goldman, N. (2006). Short-term autonomic and cardiovascular effects of Mindfulness Body Scan Meditation. Annals of Behavioral Medicine, 32, 227-234.

Evans-Chase, M. (2013). Internet-based Mindfulness Meditation and self-regulation: A randomized trial with juvenile justice involved youth. OJJDP Journal of Juvenile Justice, 3, 63-79.

Evans-Chase, M., \& Zhou, H. (2014). A systematic review of the juvenile justice intervention literature: What it can (and cannot) tell us about what works with delinquent youth. Crime \& Delinquency, 60, 453-472.

Gordon, R. (2010). Regression analysis for the social sciences. NY: Taylor \& Francis.

Greeson, J. (2009). Mindfulness research update: 2008. Complementary Health Practice Review, 14, 10-18.

Hawkins, J., Herrenkohl, D., Farrington, D., Catalano, R., Harachi, T., \& Cothern, L. (2000). OJJDP Juvenile Justice Bulletin: Predictors of youth violence. Retrieved from www.ncjrs.gov/pdffiles1/ojjdp/179065.pdf

Heinicke, B., Paxton, S., McLean, S., \& Wertheim, E. (2007). Internet-delivered targeted group intervention for body dissatisfaction and disordered eating in adolescent girls: A randomized controlled trial. Journal of Abnormal Child Psychology, 35, 379-391.

Hockenberry, S., Sickmund, M., \& Sladky, A. (2015). Juvenile residential facility census, 2012: Selected Findings. OJJDP Juvenile Offenders and Victims: National Report Series. Retrieved from http://www.ncjj.org/Publication/Juvenile-ResidentialFacility-Census-2012-Selected-Findings-.aspx

Holzel, B., Ott, U., Hempel, H., Hackl, A., Wolf, K., Stark, R., \& Vaitl, D. (2007). Differential engagement of anterior cingulated and adjacent medial frontal cortex in adept meditators and non-meditators. Neuroscience Letters, 421, 16-21.

Jain, S., Shapiro, S., Swanick, S., Roesch, S., Mills, P., Bell, I., \& Schwartz, G. (2007). A randomized controlled trial of mindfulness meditation versus relaxation training: Effects on distress, positive states of mind, rumination and distraction. Annals of Behavioral Medicine, 33, 11-21.

Levine, N. (2015). Dharma punx. Retrieved from http://www.dharmapunx.com/htm/mp3.htm

Lipsey, M., Wilson, D., \& Cothern, L. (2000). OJJDP Juvenile Justice Bulletin: Effective interventions for serious juvenile offenders. Retrieved from http://www.ncjrs.gov/pdffiles1/ojjdp/181201.pdf

Luna, B., Padmanabhan, A., \& O'Hearn, K. (2010). What has fMRI told us about the development of cognitive control through adolescence? Brain and Cognition, 72, 101-113. 
Maher, C., Williams, M., Olds, T., \& Lane, A. (2010). An Internet-based physical activity intervention for adolescents with cerebral palsy: A randomized controlled trial. Developmental Medicine \& Child Neurology, 52, 448-455.

Manzoni, G., Pagnini, F., Castelnuovo, G., \& Molinari, E. (2008). Relaxation training for anxiety: A ten-years systematic review with meta-analysis. British Medical Central Psychiatry, 8, 41-53.

Palermo, T., Wilson, A., Peters, M., Lewandowski, A., \& Somhegyi, H. (2009). Randomized controlled trial of an Internet-delivered family cognitive-behavioral therapy intervention for children and adolescents with chronic pain. Pain, 146, 205213.

Pawlow, L., \& Jones, G. (2005). The impact of abbreviated progressive muscle relaxation on salivary cortisol and salivary immunoglobulin A (sIgA). Applied Psychophysiology and Biofeedback, 30, 375-387.

Ramel, W., Goldin, P., Carmona, P., \& McQuaid, J. (2004). The effects of Mindfulness Meditation on cognitive processes and affect in patients with past depression. Cognitive Therapy \& Research, 28, 433-455.

Schnittker, J., \& John, A. (2007). Enduring stigma: The long-term effects of incarceration on health. Journal of Health \& Social Behavior, 48, 115-130.

Sedlak, A., \& McPherson, K. (2010). OJJDP Juvenile Justice Bulletin: Conditions of confinement: Findings from the survey of youth in residential placement. Retrieved from http://www.ncjrs.gov/pdffiles1/ojjdp/227729.pdf

Semple, J., Reid, E., \& Miller, L. (2005). Treating anxiety with mindfulness: An open trial for mindfulness training in anxious children. Journal of Cognitive Psychotherapy: An International Quarterly, 19, 379-392.

Smith, D., \& Ecob, R. (2007). An investigation into causal links between victimization and offending in adolescence. The British Journal of Sociology, 58, 633-660.

Snyder, H., \& Sickmund, M. (2006). Juvenile offenders \& victims: 2006 national report (Report No. NCJ 212906). Washington, DC: US Department of Justice, Office of Justice Programs, OJJDP. Retrieved from http://www.ojjdp.gov/ojstatbb/nr2006/downloads/nr2006.pdf

Tang, Y., Lu, Q., Fan, M., Yang, Y., \& Posner, M. (2012). Mechanisms of white matter changes induced by meditation. Proceedings of the National Academy of Sciences, 109, 10570-10574.

Travis, J., Cincotta, E., \& Solomon, A. (2003). Families left behind: The hidden costs of incarceration and reentry (Report No. CPR03 0105). Washington DC: Urban Institute Justice Policy Center. Retrieved from http://www.urban.org/uploadedpdf/310882_families_left_behind.pdf 
Williams, J., Duggan, D., Crane, C., \& Fennell, M. (2006). Mindfulness-based cognitive therapy for prevention of recurrence of suicidal behavior. Journal of Clinical Psychology: In Session, 62, 201-210. 